\title{
Sobre a identidade literária austríaca
}

\author{
[On Austrian Literary Identity] \\ http://dx.doi.org/10.1590/1982-88371175
}

\author{
Helmut Gollner ${ }^{1}$ \\ Tradução de Ruth Bohunovsky²
}

\begin{abstract}
Starting from the assertion that there is a separate Austrian Literary Identity (which does not want to be seen as part of German literature, but in oposition to it), the article presents arguments and examples which support this claim.
\end{abstract}

Key-words: Austrian Literature; Literary Identity; German Literature.

Resumo: Partindo da premissa de que existe uma identidade literária austríaca (que não se entende como parte da literatura alemã, mas que pretende se diferenciar dela), o artigo apresenta argumentos e exemplos que sustentam a referida argumentação.

Palavras-chave: literatura austríaca; identidade literária.

Zusammenfassung: Ausgehend von der Behauptung, dass es eine eigene österreichische Literaturidentität gibt (die nicht als Teil der deutschen Literatur gesehen werden, sondern sich teilweise klar von dieser abgrenzen will), werden Argumente und Beispiele angeführt, die diese Behauptung stützen.

Schlüsselwörter: österreichische Literatur; Literaturidentität, deutsche Literatur

\footnotetext{
${ }^{1}$ Germanista, jornalista e crítico literário em Viena, Áustria. Email: helmutgollner@gmail.com

${ }^{2}$ Universidade Federal do Paraná, Departamento de Letras Modernas, Rua General Carneiro, 460 80060-140, Curitiba, PR, Brasil. Email: ruth.bohunovsky@uol.com.br.

N. d. E. Este artigo é a versão escrita da palestra proferida por Helmut Gollner no dia 19 de setembro de 2014, na USP, São Paulo, e no dia 24 de setembro de 2014, na UFSC, Florianópolis. Trata-se de texto original, cuja tradução ao português foi autorizada pelo autor para publicação na Pandaemonium Germanicum.
}

Pandaemonium, São Paulo, v. 18, n. 25, Jun. /2015, p. 1-17. 


\section{Introdução}

Uma conferência sobre literatura austríaca parte da premissa de que ela existe. Essa afirmação não é óbvia, uma vez que a literatura austríaca é escrita, grosso modo, na mesma língua que a literatura alemã e a suíço-alemã. Ou seja, ao afirmar a existência e a especificidade de uma literatura austríaca, é preciso apresentar um bom número de justificativas, sobretudo para uma diferenciação em relação à literatura alemã escrita na mesma língua. A discussão sobre uma literatura austríaca existe há mais de cem anos e, sobretudo após 1945, a existência de uma identidade cultural austríaca sui generis foi um assunto polêmico e alvo de veementes debates, vinculados a especulações históricas e ideológicas que não posso abordar aqui.

Hoje, tanto a germanística austríaca quanto a internacional concordam que é preciso falar de uma literatura austríaca autônoma. $\mathrm{O}$ motivo resumido para isso: as diferenças histórico-sociais e, portanto, intelecto-culturais em relação à Alemanha resultam para a Áustria numa história literária e numa identidade literária divergente. Falar a mesma língua não é sinônimo de uma identidade compartilhada. É óbvio que a literatura americana não se entende como parte da literatura britânica e que a literatura brasileira não se entende como parte da literatura portuguesa.

É óbvio também que, ao apontar as diferenças entre a literatura austríaca e a alemã, não se pretende negar as afinidades. Mas, afirma-se que para uma compreensão adequada de muitas das obras da literatura austríaca é necessário considerar o contexto austríaco. A historiografia literária alemã e a crítica literária nos jornais alemães têm certa dificuldade de entender esse fato, seja em relação a Franz Grillparzer ou a Elfriede Jelinek. São as semelhanças que dominam.

Quero me deter em duas características da literatura austríaca que a diferenciam da alemã: 1. Um elevado ceticismo em relação à imagem humanista do homem e 2 . Um elevado ceticismo em relação à linguagem. 


\section{Ceticismo em relação ao humanismo}

A periodização da história literária alemã a partir do século XVIII é conhecida: Iluminismo, Sturm und Drang [Tempestade e Ímpeto], Classicismo, Romantismo, Realismo burguês, Materialismo antiburguês, Naturalismo etc.

Essas categorias históricas são pouco úteis para se entender a literatura austríaca dos séculos XIX e XX. Entre as obras que se tornaram canônicas, nós não temos o Iluminismo, não temos o Classicismo, nem o Romantismo etc.

Ou, dito em outras palavras: A emancipação do Eu, esse grande projeto cultural da modernidade europeia que foi realizada com o Renascimento e, mais tarde na Alemanha com o Iluminismo, com Kant, Goethe e Schiller, essa libertação do espírito humano, a valorização do homem como "a coroa da criação divina”, na Áustria, tudo isso fez efeito de modo diferente e mais tarde, e sobretudo foi muito menos veemente. Ou, de modo taxativo: em vez de Kant, Lessing, Schiller, Hegel, Marx e Brecht, a Áustria tem Grillparzer, Freud, Kafka, Schnitzler - todos eles sabem da falta de liberdade do Eu ou têm receio da sua libertação. Nossa literatura não foi marcada nem pela emancipação racional do Iluminismo (pensar é suficiente para alcançar a verdade e a felicidade), nem pela emancipação emocional do Sturm e Drang (todo o direito para o indivíduo e seus sentimentos!) que se prolongou até o Romantismo, nem pelo idealismo do Classicismo (o homem é ilimitado para a humanidade) e nem pelas utopias sociais do século XIX (o homem pode melhorar com mudanças na sociedade).

Então, a literatura austríaca do século XIX é marcada por quais influências? Ela oferece psicologia (o interesse pelo homem como é, não como deveria ser); ela presume a determinação do homem (querer é ter que); ela evidencia um pessimismo cultural (o progresso leva à decadência) e um profundo ceticismo em relação a ideologias e outras promessas de felicidade.

É importante frisar que as afirmações aqui apresentadas devem ser entendidas de modo relativo, elas são feitas aqui em termos absolutos apenas para realçar os aspectos centrais deste pequeno panorama. Trata-se de tendências, não de toda a verdade sobre a literatura austríaca.

A pergunta pelo motivo do desenvolvimento diferente da literatura austríaca em relação à alemã não tem resposta fácil em termos científicos. A maioria das respostas 
remete ao Império Habsburgo e ao Catolicismo - ambos são forças antiempancipatórias, dominantes durante séculos.

Para não deixar minhas afirmações sobre a literatura austríaca sem exemplos ilustrativos, seguem algumas características resumidas dos autores mais renomados do século XIX:

Franz GRILLPARZER (1792-1881) foi um criador extraordinário de figuras humanas; sua profundidade psicológica as faz suscetíveis para as teorias de Sigmund Freud - 50 anos antes. Grillparzer foi um homem esclarecido que admirou a revolução francesa, Schiller, Goethe e Kant. Mas, por medo da libertação/emancipação do homem, tornou-se um monarquista conservador, um antidemocrata. Seu pessimismo cultural: Grillparzer estava convencido de que a libertação do indivíduo libertaria apenas seu egoísmo, a emancipação do homem libertaria apenas o animal no homem.

Também Johann NeSTROY (1801-1862) não acreditou que o homem fosse bom. Seus dramas estão repletos de crítica mordaz em relação ao homem, sua condição de vida e sua fé no progresso. O homem é incorrigível. E, como todo pessimista cultural, Nestroy era necessariamente conservador, já que não acreditava na possibilidade de melhorar, apenas na de piorar o mundo. Assim, Nestroy também foi monarquista, apesar da sua língua crítica, que lhe rendeu até um tempo na cadeia.

Nas peças fantásticas de Ferdinand RAIMUND (1790-1836), o homem é salvo apenas por mágicos e fantasmas bondosos. Ele mesmo não consegue se salvar. O homem não é livre, apenas as crianças.

Na obra de Adalbert STIFTER (1805-1868) são a religião e a moral burguesa que ditam ao homem o que ele pode fazer e pensar. Também para Stifter, a emancipação do Eu ganha dimensões catastróficas: significa a libertação das paixões, e a libertação de paixões significa destruição.

A literatura austríaca do século XIX desconfia do homem - e essa desconfiança o impede de reivindicar sua emancipação (ou: ela conhece tão bem o homem que não ousa desejar sua emancipação).

Quando surgiu uma literatura austríaca de referência mundial, na primeira metade do século XIX, Goethe ainda estava vivo e o humanismo burguês ainda possuía, em larga escala, o poder de definição cultural. A era burguesa na Alemanha (com seu auge literário no Classicismo de Weimar) tinha desenvolvido uma imagem otimista do homem, com base no Iluminismo, no Cristianismo e no Idealismo: 
Gollner, H. - Identidade literária austríaca

- O homem é bom, quando quer.

- Sua vontade é livre.

- Suas habilidades intelectuais (a cultural, a moral) o elevam a uma posição superior à matéria e ao animal, inclusive a uma posição superior ao animal no homem.

- O pensamento garante o aperfeiçoamento do homem e a evolução do mundo, ou seja, garante o progresso.

O pós-humanismo, hoje proferido sobretudo pela filosofia francesa, instalou-se na Áustria já no século XIX: o homem não é livre, nem externa nem internamente, seu pensamento representa os próprios desejos e, portanto, torna o homem mais perigoso do que qualquer animal.

Tendo em vista à história europeia, isso soa quase como uma profecia. Entre o otimismo burguês da época de Goethe e hoje, temos um século XX com as maiores catástrofes da história da humanidade: uma Primeira Guerra Mundial com dez milhões de mortos, uma Segunda Guerra Mundial com cinquenta milhões de mortos e um genocídio industrial de seis milhões de judeus. O progresso da humanidade revelou-se como a vitória da inumanidade e, para o futuro, significa a ameaça da destruição da terra.

A imagem humanista do mundo foi brutalmente falsificada. A mais tardar depois de 1945, o pós-humanismo austríaco se tornou um anti-humanismo que, com sua agressividade e sua dominância, diferencia-se claramente da situação alemã.

Com isso, estamos no presente. Como ainda acreditar no homem, depois das atrocidades incomensuráveis dos nazistas? Os nazistas não foram os outros, mas, em boa parte, nossos pais e avós. Supõe-se que o humanismo burguês forneceu informações erradas sobre o homem nas quais baseou uma falsa cultura.

Como acreditar numa cultura cuja força reunida (da democracia grega até as mensagens de amor do cristianismo, da revolução francesa até o socialismo) não teve forças suficientes para evitar Hitler? Na literatura austríaca pós-1945 há fortes dúvidas e uma ruptura afetiva em relação à nossa cultura.

Como ainda acreditar na possibilidade de um sentido ou participar de uma nova produção de sentido, se os nossos sistemas de sentido, em forma de ideologias, fizeram da terra um campo de batalha? Quem produz sentido, levanta suspeitas de ser um Pandaemonium, São Paulo, v. 18, n. 25, Jun. /2015, p. 1-17 
assassino. De um modo geral, a vertente mais radical da literatura austríaca não sente vontade de interpretar o mundo, mas de destruir sentido.

Exemplo número 1: O assim chamado Grupo de Viena, que atuou no final dos anos 1950 e no início dos anos 1960, realizou de modo mais radical a destruição de cultura. O convite foi para um "evento cultural" no centro de Viena: numa pequena mesa, uma máquina de escrever, com uma folha de papel inserida. Com um chicote (com bolinhas de chumbo nas pontas), bateu-se nas teclas; no papel inserido, surgem letras e sinais de pontuação; tirou-se o papel da máquina e a folha foi leiloada entre os presentes, como nova literatura. Em Viena, costuma-se servir café e bolo em eventos culturais; os cinco autores do Grupo de Viena também fizeram isso: em pequenos xícaras e pratos de brinquedo.

Isso provoca e é divertido; raramente, a destruição austríaca de cultura abre mão da diversão. A postura atrás da diversão: uma total recusa de cultura, a frustração de qualquer expectativa burguesa em relação à arte: que a literatura tem de ser bonita, que literatura tem de ter um sentido ou, pelo menos, um autor. Oswald WIENER, o mais radical entre os críticos culturais do Grupo de Viena: "Temos que fazer qualquer coisa para destroçar as ideias do Eu, do espírito, da língua e do sentido" (JANDL 1997).

Exemplo número 2: Sabe-se que o Fausto de Goethe é o herói do modelo burguês-humanista de sucesso: a vida humana tem um sentido; Fausto o busca, o encontra e o realiza; Deus protege Fausto (o homem) e o salva do diabo. Na literatura alemã, Fausto é o exemplo mais famoso para o homem que, no final, dá certo, para o homem do otimismo burguês que, no final, é feliz.

Já no século XIX, os austríacos Franz Grillparzer (num rascunho) e Nikolaus Lenau (num drama épico em versos) encenaram o fracasso do modelo fáustico do homem que procura e encontra o sentido. Na literatura austríaca contemporânea existem oito (!) dramas que são releituras do inimigo preferido Fausto; todos eles destroem o humanismo goetheano. Vou dar um exemplo.

Em 1987, Wolfgang BAUER (1941-2005) escreveu uma peça com o título Senhor Fausto joga roleta [Herr Faust spielt Roulette]. O senhor Fausto está sentado num cassino, numa mesa de roleta. Ao longo do enredo grotesco, Fausto vai perdendo tudo que tinha sido usado por Goethe e por Deus para defini-lo, ou para protegê-lo. Perde-se o sentido, perdem-se a lógica e a casualidade, perde-se a realidade, o espaço e o tempo, e perde-se até a identidade. Por fim, ninguém mais sabe quem é o senhor Fausto, nem 
Gollner, H. - Identidade literária austríaca

ele mesmo, e nem se sabe por qual motivo ele está nessa peça. - O que fará um clássico gigante do Eu, um gigante do sentido, com um Eu sem chão e sem sentido?

Pede-se ajuda a Goethe! Ele certamente poderá ajudar e fornecer uma identidade e um sentido. O senhor Goethe entre em cena, é apresentado ao senhor Fausto, mas não o reconhece e não tem como salvar a peça, nem como oferecer uma identidade. E ele também não mostra o mínimo interesse para tal, mas se senta à mesa de roleta, junto com o senhor Dostoievski, que (como vocês sabem) foi um jogador apaixonado e já se encontra no cassino.

Por fim, não resta outra possibilidade a não ser chamar ao palco o próprio autor da peça, Wolfgang Bauer, o culpado de tal catástrofe dramática. Quando o chamam, Bauer está justamente trabalhando na peça que está sendo encenada. Ele é arrastado da máquina de escrever para o palco. Mas o senhor Bauer também não sabe quem poderia ser o senhor Fausto. E há outro problema: a peça nem está pronta ainda e termina sem ser escrita. O que será do senhor Fausto? Qual o sentido de ter passado essa noite no teatro? Bauer encolhe os ombros, já está sentado junto à mesa de roleta, com seus colegas Goethe e Dostoievski. Graças a Deus, o Chanceler austríaco se encontra na plateia: ele propõe simplesmente manter o cassino funcionando (já que o Estado da Áustria ganha dinheiro com isso), sem pensar muito sobre quem é o autor da peça ou sobre o que ela quis dizer. Todos estão de acordo.

E Fausto fica para trás; sem sua proteção ocidental de realidade e identidade, abandonado por todos os seus autores, no meio da Áustria. Numa peça absurda, o Fausto sério torna-se mais desamparado do que uma criança.

A fuga do autor da sua própria peça é uma consequência da recusa geral de sentido, a um só tempo atraente e provocativa. "É muito caótico aqui", Fausto diz já durante a peça, "aqui não acontece nada, há apenas caos e um pouco de diversão", nenhuma verdade, nenhuma redenção através do conhecimento. E esse escândalo humanista, essa mera fuga do sentido, tudo isso parece ser divertido. De um modo mais atrevido e muito simplificado, seria possível resumir: um visitante alemão se depara com o contexto intelectual austríaco e fracassa miseravelmente com sua habilidade cultural de tornar o mundo um lugar aconchegante com as verdades.

Exemplo número 3: Ernst JANDL (1925-2000), um dos líricos mais importantes da Áustria, procurou durante toda a sua vida/escrita corroer as bases da cultura burguesa- 
humanística, ao negar a ela uma linguagem bonita assim como temas importantes. Existe um poema de Jandl que eu consegui decorar, é o seguinte (JANDL 1997: 71):

$\begin{array}{ll}\text { Nein } & \text { não } \\ \text { nein } & \text { não } \\ \text { nein } & \text { não } \\ \text { nein } & \text { não } \\ \text { nein } & \text { não } \\ \text { nein } & \text { não } \\ \text { nein } & \text { não }\end{array}$

Esse poema tem um subtítulo: Resposta para sete perguntas não feitas. Jandl abana a cabeça em sinal de desaprovação, antes de saber as perguntas. Ele não tem respostas; nega-se a fazer parte do vozerio de respostas em que ressoam um século inteiro e toda uma cultura; assim como Bauer, Jandl se recusa a fazer uma afirmação.

Outro poeta austríaco famoso é Rainer Maria RILKE (1875-1926). Há bibliotecas inteiras sobre sua obra e sua vida, cheias de interpretações sérias e significações. Ernst Jandl também quer dizer algo sobre Rilke, por exemplo, sobre o sapato de Rilke ou sobre o copo de Rilke (JANDL 1997).

$\begin{array}{ll}\text { rilkes schuh } & \text { o sapato de rilke } \\ \text { war einer } & \text { foi um } \\ \text { von zweien } & \text { de dois } \\ \text { jeder schuh rilkes } & \text { cada sapato de rilke } \\ \text { war einer } & \text { era um } \\ \text { von zweien } & \text { de dois } \\ \text { rilke in schuhen } & \text { rilke de sapatos } \\ \text { trug immer } & \text { calçou sempre } \\ \text { zwei } & \text { dois } \\ \text { wade an wade } & \text { panturrilha com panturrilha } \\ \text { stand rilke } & \text { rilke saiu } \\ \text { aus den beiden schuhen heraus } & \text { dos dois sapatos. }{ }^{3}\end{array}$

Ou sobre o copo de rilke (JANDL 1997):

rilke nahm ein glas

füllte es mit wasser hob es zum mund

trank rilke pegou um copo encheu-o com água levantou-o até a boca bebeu

\footnotetext{
${ }^{3}$ Tradução gentilmente cedida por Fabiana Macchi.

Pandaemonium, São Paulo, v. 18, n. 25, Jun. /2015, p. 1-17.
} 
Assim reage alguém que não consegue mais manter a seriedade no grande empurraempurra de significações da nossa cultura, Jandl perdeu toda a vontade e capacidade de estar convencido de algo. Todas as convenções contêm uma boa porção de estupidez, sua seriedade tem algo de ridículo e, ainda por cima, são perigosas.

Nós não somos o Fausto. Jandl não é um humanista alegre, mas profundamente depressivo na sua visão de mundo. O homem não possui a constituição de Fausto, não é um atleta do Eu e da cultura, o homem tem uma constituição pequena, como um anão, é cheio de falhas, é ridículo. "A dimensão humana para o mundo é sem validade, a linguagem e a temática desses poemas ficam próximas ao chão, a cabeça alcança uma altura como a da ovelha, do cão ou do pássaro na relva." (JANDL 1980: quarta capa). O Renascimento, o Iluminismo e o Humanismo chegaram ao seu fim, a emancipação histórica do Eu só evidenciou a mesquinhez do homem. De modo bastante consequente, Jandl constata isso também em relação à sua própria pessoa (JANDL 1997: 225).

schritte

der nebel

den berg

der berg

den baum

der baum

das blatt

das blatt

den käfer

der käfer

mich

Passos
a neblina
à montanha
a montanha
à árvore
a árvore
à folha
a folha
ao besouro
o besouro
a mim

Numa comparação de tamanho entre os fenômenos naturais, o Eu ocupa o último lugar, depois do besouro. $O$ texto não tem predicados, mas ele tem uma gramática ${ }^{4}$ : a sequência de nomes no nominativo e no acusativo remete à relação entre sujeito e objeto. Na hierarquia da sentença, essa relação é também uma relação de poder, o sujeito determina (através do predicado) o objeto. Todos os fenômenos naturais têm o direito de constar, uma vez, no nominativo e, com isso, ser um orgulhoso sujeito. Apenas para o Eu não há nominativo, resta-lhe a impotência do objeto no acusativo. Além disso, a construção segue exatamente o modelo do poema de natureza alemão clássico-romântico, mas em oposição a ele. O Eu do poema alemão sobre natureza entra

\footnotetext{
${ }^{4}$ N.T. A argumentação a seguir refere-se apenas ao poema em alemão e suas relações gramaticais.

Pandaemonium, São Paulo, v. 18, n. 25, Jun. /2015, p. 1-17.
} 
Gollner, H. - Identidade literária austríaca

na floresta e sempre encontra - a si mesmo. O objetivo da visita lírica à natureza é sempre o homem. Jandl passa pela natureza como Goethe no seu famoso poema Ein Gleiches: em primeiro lugar, a natureza anorgânica: neblina, montanha ("sobre todos os cumes reina a paz"), depois a flora: árvore, folha (“em todas as copas mal sentes um sopro"), depois a natureza animal: o besouro ("os pássaros silenciosos na floresta"), para finalmente chegar ao Eu (“Espera! Em breve descansarás também!’). Porém, em Goethe, o passeio pela natureza leva ao consolo do Eu; em Jandl, ele leva à degradação do Eu.

Um Eu de besouro, um Eu de melro na relva, um Eu de cão ou de ovelha não tem mensagens, não persegue os grandes temas (JANDL 1980):

themen

die großen

themen

kommen

mit den tiefen einsichten

mein rechter

daumen

wenn ich ihn ansehe

fordert mich

zum arzt

schon lange

es geht

von ihm

was weg temas

os grandes

temas

vêm

com os profundos conhecimentos

meu polegar

direito

quando olho para ele

exige que eu vá

ao médico

há muito tempo

tem algo

que dele

se solta

Jandl zomba da poesia das grandes mensagens. É através dos "profundos conhecimentos" [Einsicht literalmente "visão para dentro"] que se chega aos "grandes temas". Então, ele olha bem de perto o seu polegar: o "profundo conhecimento" resulta num "grande tema": o meu polegar precisa de cuidados médicos. A observação detalhada me leva não a uma verdade mais elevada, mas ao médico. Isso é o escárnio do espírito através da banalidade do corpo. "es geht / vom ihm / was weg" soa como um murmúrio de uma mensagem enigmática, mas é apenas a unha ou a pele que se solta do polegar. "Não conheço nada que seja banal", diz Jandl na sua fala de agradecimento em ocasião do recebimento do Prêmio para Dramaturgia de Mühlheim, em 1980, “a não ser, talvez: os grandes temas... os profundos conhecimentos". Numa palestra, Jandl citou o 
Gollner, H. - Identidade literária austríaca

músico experimental americano John Cage: "Não tenho nada a dizer / e o digo / e isso é a poesia / como eu a preciso."

Jandl não diz nada. Um dos seus poemas sem sentido, de três versos, tem o título als dieses [como tal] (JANDL 2011: 88):

natürlich

können gedichte länger sein

als dieses obviamente

há poemas mais cumpridos

que este

\section{Ceticismo linguístico}

A característica da literatura austríaca mais aceita como tal no âmbito acadêmico e crítico é sua consciência linguística extremamente evidente. O que marca a literatura austríaca numa extensão significativa é o ceticismo linguístico (que vai até a recusa ou a destruição da língua), a reflexão sobre a língua (na literatura e na filosofia), assim como experimentos e jogos linguísticos.

Isso começou, a mais tardar, no século XIX com Johann NESTROY (1801-1862), o mordaz crítico linguístico, artista da língua e atrevido jogador de linguagem. A famosa "Carta a Chandos", de Hugo von Hofmannsthal (1874-1929) articula a crise moderna da língua, em que se desfaz a evidência do uso da língua. Aproximadamente ao mesmo tempo, o escritor e filósofo Fritz MAUTHNER (1849-1923) colocou em questão a capacidade da língua de representar a verdade. No interregno entre as duas guerras, Karl KRAUS (1874-1936) exercia sua crítica linguística tão incorruptível quanto implacável: a língua como moral. Temos que nos deter um pouco mais em Ludwig WITTGENSTEIN (1889-1951), visto que ele exercia uma influência enorme na literatura austríaca pós-1945.

O caso histórico de Kaspar Hauser é bastante conhecido: Kaspar apareceu em 1828 numa praça em Nürnberg; estima-se que tinha dezesseis anos, estava absolutamente descuidado em termos físicos, sem linguagem articulada, praticamente um animal. Mais tarde, contou que tinha crescido num tipo de porão, recebendo alimentação, mas nenhuma língua, ninguém falava com ele. Inicialmente, só sabia falar uma única frase: "Quero ser cavaleiro, igual ao meu pai”. O jovem, um caso com um tanto de encanto circense, foi acolhido pela cidade, foi civilizado aos poucos e se tornou 
Gollner, H. - Identidade literária austríaca

o centro de atenção dos sensíveis salões culturais, socialmente integrado mas psicologicamente estropiado. A sociedade burguesa sentia orgulho por ter transformado, em pouco tempo, um animal numa pessoa. Cinco anos depois do seu aparecimento, foi assassinado. Era descendente de uma família aristocrata, seus assassinos eram de uma família rival. Essa narrativa não resiste à revisão científica. Mas isso não interessa neste momento.

Peter HANDKE (1942) elaborou uma abstração do caso da integração social problemática de Kaspar Hauser, numa peça dramática de 1968 sobre uma integração linguística problemática.

A peça se chama Kaspar. O Kaspar de Handke entra no palco com uma versão generalizadora da frase de Kaspar Hauser: "Quero me tornar alguém que já tenha sido um outro". Começa o trabalho da sociedade. Os "sussurradores" introduzem Kaspar com altofalantes à língua, à sua estrutura e a seus costumes, até, no final, Kaspar dominar tão bem a língua que o palco se enche com pequenos Kaspars que querem aprender com ele. Sua última frase, antes de deixar o palco: "Sou eu apenas por acaso".

A língua fez de Kaspar um ser tão conformado que ele perdeu seu Eu individual.

O rumo da socialização linguística de Kaspar acompanha a filosofia de Ludwig Wittgenstein.

No seu cerne, essa filosofia (pelo menos nas Investigações filosóficas, 1953) sustenta que a língua, nas suas estruturas, é um sistema marcado socialmente. Não somos usuários livres da nossa língua, mas falamos automaticamente a cultura da comunidade linguística à qual pertencemos. O léxico, a sintaxe e a idiomática contêm valores, ideologias e relações de poder da sociedade que os fala. Falamos dentro das condições que a língua nos dá. Dito de modo exagerado: Não falamos, somos falados. Quase o mesmo acontece com o pensamento que não existe sem língua. Kaspar reconhece que, ao aprender a língua, ele cede a soberania do seu Eu (da sua fala e do seu pensamento) à sociedade: "Sou eu apenas por acaso".

Wittgenstein chamou as regras da língua "jogo de linguagem": "O jogo de linguagem não tem sua origem na reflexão. A reflexão é parte do jogo de linguagem". Ele disse também: “Toda filosofia é crítica linguística". Antes de filosofar sobre o mundo, precisaríamos averiguar se a língua é capaz de representar o mundo de modo correto, se ela é capaz de falar sobre a verdade. Esse entendimento trouxe consequências abrangentes na literatura austríaca após 1945. A certeza cada vez mais 
Gollner, H. - Identidade literária austríaca

firme de que com a língua não se representa o mundo, mas a visão de mundo da comunidade linguística, levou a um foco na própria língua, para com ajuda dela, mostrar a sociedade (isso vale tanto para o jovem Handke quanto para Elfriede Jelinek). Tornouse cada vez mais difícil utilizar a língua de modo ingênuo, a literatura tinha que refletir também sobre ela. Com apenas vinte e quatro anos, de óculos e com um penteado estilo Beatles, Peter Handke, tão discreta quanto explicitamente, comunicou isso à alta sociedade literária do grupo 47, no seu encontro em Princeton em 1966.

Já comentei o decorrer catastrófico da nossa história mais recente (guerras mundiais, holocausto). Essa desumanidade histórica coloca em questão não apenas toda a nossa cultura, mas natural e especialmente também a nossa língua, sobretudo para quem quer fazer literatura com ela. Como devemos falar, se não podemos acreditar mais na tradicional beleza poética? Qual linguagem abarca todo o sofrimento do nosso tempo? Como fazer poesia depois de Hitler?

Vou dar apenas dois exemplos. Primeiro, um poema de Paul CELAN (19201970), que é difícil de entender sem ajuda da germanística. Mas, ele aborda justamente motivos por que um poema pode ou deve também ser difícil (CELAN 1980):

\section{Tübingen, Jänner}

Zur Blindheit über-

redete Augen.

Ihre - ,ein

Rätsel ist Rein-

entsprungenes“"-, ihre

Erinnerung an

schwimmende Hölderlintürme, möwen-

umschwirrt.

Besuche ertrunkener Schreiner bei

diesen

tauchenden Worten:

Käme,

käme ein Mensch,

käme ein Mensch zur Welt, heute, mit

dem Lichtbart der

Patriarchen: er dürfte,

spräch er von dieser

Zeit, er

dürfte

nur lallen und lallen,

immer-, immer-

\section{Tübingen, Janeiro}

Olhos per-

suadidos à cegueira.

A sua - "um

enigma é o puro

brotar" - a sua

recordação de flutu-

antes torres de Hölderlin, gai-

votas ao redor.

Visitas de carpinteiros afogados

Com estas

palavras submergindo:

Se viesse,

viesse um homem

viesse um homem ao mundo, com

a barbaluz dos

Patriarcas: só diria,

se falasse deste

tempo, só

balbucio, balbucio,

tal, tal. 
zuzu.

("Pallaksch. Pallaksch")

(,Pallaksch. Pallaksch.“)

Tübingen é uma cidade universitária na Alemanha que Celan visitou num mês de janeiro. Mas Tübingen é também aquela cidade em que Friedrich HöLDERLIN (17701843) passou seus últimos trinta e seis anos de vida, mentalmente alienado, com esquizofrenia. Morava num quarto numa torre ("Torre de Hölderlin") na casa do carpinteiro que tomava conta dele. Paul Celan admirava Friedrich Hölderlin e, assim como ele, estava convencido que o verdadeiro poeta teria a capacidade de ver a verdade atrás das coisas, ou seja, que teria habilidades proféticas. Todos os profetas da mitologia antiga são cegos e, por isso, não distraídos pela aparência externa das coisas (“Olhos persuadidos à cegueira").

Mas eu vou interpretar apenas a segunda parte do poema, mais importante para nossa discussão. "Com estas palavras submergindo": essa imagem pertence à metáfora aquária mais abrangente do poema. Palavras de poeta não denominam apenas as coisas, mas mergulham fundo até sua origem. Lá, mergulhando, eles encontram aquilo que é o indizível do nosso tempo: "Se viesse, viesse um homem" etc. Celan precisa começar a frase três vezes, antes de conseguir terminá-la. "Com o barbaluz dos patriarcas" significa, se traduzirmos rapidamente: com as capacidades proféticas do poeta. Ou seja, se hoje viesse ao mundo um verdadeiro poeta para falar deste tempo, do tempo presente de Celan, ele apenas conseguiria balbuciar. E o próprio Celan começa a balbuciar um pouco, para poder falar o convencional mais verdadeiro do que bonito.

Não há língua que possa abarcar a infelicidade ou a dor deste tempo, e muito menos a nossa língua de cultura com sua reivindicação de lógica, sentido e beleza. Toda língua já contém na sua estrutura (na gramática, sintaxe, idiomática...) as convenções culturais da sua comunidade linguística. Para poder falar de modo mais verdadeiro do nosso tempo, seria preciso voltar para uma forma pré-cultural, pré-linguística, que ainda não incluísse na sua estrutura os falsos apaziguamentos de ordem, sentido e beleza que, pela mera existência dessa estrutura, já divulgam mentiras sobre a verdade.

É importante lembrar que Celan era judeu, que a maior parte da sua família foi assassinada pelos nazistas, inclusive sua amada mãe, e que Celan cometeu suicídio aos cinquenta anos, em Paris.

\footnotetext{
${ }^{5}$ N.T. Tradução de Adalberto Müller (http://cordeldigital.blogspot.com.br/2008/09/celan-hoelderlin.html) Pandaemonium, São Paulo, v. 18, n. 25, Jun. /2015, p. 1-17.
} 
Para mim, a parte mais triste do poema é a última linha: Friedrich Hölderlin, como muitos esquizofrênicos, desenvolveu sua própria língua, incompreensível para outros. Nessa língua, uma palavra recorrente foi "Pallaksch", que não se encontra em nenhum léxico. Amigos suspeitaram que ela significasse ou "sim" ou "não". Mas ninguém sabe o que realmente significa. Se Celan coloca no final do seu poema duas vezes o incompreensível "Pallaksch", então ele quer dizer: Hölderlin já o fez e eu também estou me preparando para fechar minha língua, pois numa língua compreensível não é possível comunicar o nosso sofrimento. (Isso é também um saber da tradição do chassidismo: o sofrimento do mundo é inefável). O poema de Celan fala tanto dos motivos quanto das consequências nossa pobreza cultural/ linguística.

O segundo exemplo: Tudo o que Ernst Jandl fez com a língua pode ser chamado de contestação cultural por excelência. Jandl nega/destrói dentro da cultura caída (a do humanismo burguês) a sua língua aprumada, ao tornar feio o que ela tinha de bonito, ao idiotizar o que ela tinha de inteligente, ao banalizar o que estava cheio de sentido e ao materializar seu lado espiritual. Jandl deforma a estrutura eufemística da nossa língua de cultura.

O poema crítico mais popular, mais taxativo, mas que não é o melhor de Jandl, é schtzngrmm. Jandl demonstra, com ajuda da palavra bélica SCHÜTZENGRABEN [trincheira], a sua tese de que a língua torna o mundo sempre mais bonito do que ele é.

Mais um pouco de filosofia da linguagem: Quando falamos em frases sobre a realidade, a submetemos ao sistema lógico da sintaxe; falando, colocamos o mundo em ordem. Cada palavra atribui a uma coisa seu significado. Através da semântica da língua, nossa fala é uma constante distribuição de significados; geralmente não abrimos a boca para outra coisa. Em terceiro lugar, cada língua tem sua estética involuntária; na literatura, ela se torna voluntária; utilização da língua significa estetização do mundo. A língua fornece ao mundo ordem, sentido e beleza. A palavra schützengraben tem um conteúdo dos mais feios: sangue, morte, sujeita, ou seja, guerra. A aparência fonética da palavra não contém nada disso; as palavras não são as coisas, mas nomes inofensivos. Como tudo na língua, schützengraben soa bonito demais para a realidade que comunica. A guerra nem soa nunca, ela faz barulho.

Numa reflexão bem teórica, Jandl afasta então da palavra todas as partes que soam, ou seja, as vogais, e deixa para as consoantes a tarefa de transformar a palavra em barulho. Assim, schützengraben se torna schtzngrmm [trnchr]. Jandl faz uma imagem acústica 
com o intuito de estar mais perto da realidade da guerra do que a palavra inicial (JANDL 1976: 38-39).

\begin{tabular}{ll} 
Schtzngrmm & trnchr \\
schtzngrmm & trnchr \\
schtzngrmm & trnchr \\
t-t-t-t & t-t-t-t \\
t-t-t-t & t-t-t-t \\
grrrmmmmm & trrrnnnn \\
t-t-t-t & t-t-t-t \\
s----------c-----------h & c----------h------------r \\
tzngrmm & rnchr \\
tzngrmm & rnchr \\
tzngrmm & rnchr \\
grrmmmmm & trrrnnnnn \\
schtzn & trn \\
schtzn & trn \\
t-t-t-t & t-t-t-t \\
t-t-t-t & t-t-t-t \\
schtzngrmm & trnchr \\
schtzngrmm & trnchr \\
tsssssssssssssss & trrrrrrrrrrrrrrrrr \\
grrt & grrn \\
grrrrrt & grrrrrn \\
grrrrrrrrt & grrrrrrrrn \\
scht & trn \\
scht & trn \\
t-t-t-t-t-t-t-t-t-t & t-t-t-t-t-t-t-t-t-t \\
scht & trn \\
tzngrmm & rnchr \\
tzngrmm & rnchr \\
t-t-t-t-t-t-t-t-t-t & $\mathrm{t}-\mathrm{t}-\mathrm{t}-\mathrm{t}-\mathrm{t}-\mathrm{t}-\mathrm{t}-\mathrm{t}-\mathrm{t}-\mathrm{t}-\mathrm{t}$ \\
scht & trn \\
scht & trn \\
scht & trn \\
scht & trn \\
scht & trn \\
grrrrrrrrrrrrrrrrrrrrrrrrr & grrrrrrrrrrrrrrrrrrrrrrrrr \\
t-tt & $\mathrm{t}$-tt \\
& \\
\hline
\end{tabular}

\section{Referências bibliográficas}

GOLLNER, Helmut, Die Rache der Sprache: Hässlichkeit als Form des Kulturwiderstands in der österrichischen Gegenwartsliteratur. Innsbruch: Studieniverlag, 2009. 
GOLLNER, Helmut; ZEYRINGER, KlAUS, Eine Literaturgeschichte: Österreich seit 1650. Innsbruck, Wien, Bozen: Studienverlag, 2012.

JANDL, Ernst, Laut und Luise. Stuttgart: Reclam, 1976.

JANDL, Ernst, der gelbe hund. München: Luchterhand, 1980.

JANDL, Ernst. Poetische Werke. Frankfurt am Main: Suhrkamp, 1997.

JANDL, Ernst, Letzte Gedichte. Frankfurt am Main: Suhrkamp. 2001.

Celan, Paul, Die Niemandsrose. Sprachgitter. Gedichte. Frankfurt am Main: Fischer, 1980.

Recebido em 15/10/2014

Aceito em 15/11/2014 